\title{
Comparison of genetic variation in growth performance on normal and novel host plants in a local population of a herbivorous ladybird beetle, Epilachna vigintioctomaculata
}

\author{
HIDEKI UENO*†+, YUKO HASEGAWA $\dagger$, NAOYUKI FUJIYAMA§ \\ \& HARUO KATAKURA§ \\ $\dagger$ Laboratory of Biology, Faculty of Education, Niigata University, Niigata 950-2181 Japan, \\ $\$$ Van der Klaauw Laboratory, Institute of Evolutionary and Ecological Sciences, PO Box 9516, 2300 RA Leiden, \\ The Netherlands and §Laboratory of Systematics and Evolution, Graduate School of Science, Hokkaido University, \\ Sapporo 060-0810 Japan
}

\begin{abstract}
Local populations of herbivore species that display variation in host plant use are subject to natural selection for improved ability to use their own host species. Since natural selection changes the frequency of alleles that control host use, genetic variation in growth performance on host plants may change with each generation of selection. Therefore, within-population variations in the ability to use different hosts may reflect past selective forces. The present study reports the genetic variation in growth performance in a population of the herbivorous ladybird beetle, Epilachna vigintioctomaculata Motschulsky (Coccinellidae, Epilachninae) on both the normal host and a novel host. The present study found higher heritabilities for growth performance on the novel host than the normal host. The difference in heritabilities was caused by smaller among-family variance components on the normal host compared to those on the novel host. The results are compatible with the view that natural selection, which improved the ability of the population to use a particular host plant, has reduced genetic variation within that population in the ability to use that host plant. The pattern of reduced genetic variation in a population reared on the normal host observed in the present study is compared with that in another population, which showed local adaptation in the use of its own host plant. The effect of natural selection on differing host plant use on within-population genetic variation is discussed.
\end{abstract}

Keywords: Epilachna vigintioctomaculata, genetic variation, host plants, local adaptation.

\section{Introduction}

Estimation of the magnitude of genetic variation both within and among populations is essential to understand the dynamics of host plant adaptation (Via, 1990). Local populations of a polyphagous herbivore species found on different hosts may diverge, as each is subject to natural selection for improved ability to use its own host species. Therefore, variation in host plant use between populations can reveal patterns of local adaptation and suggests a response to past selective forces (Via, 1991).

\footnotetext{
*Correspondence and present address: Laboratory of Biology, Faculty of Education, Niigata University, Niigata 950-2181 Japan. E-mail: hueno@ed.niigata-u.ac.jp
}

To understand the process of host plant adaptation in each population, however, requires elucidation of the presence and nature of genetic variation and covariation in differing host use within these populations. Evolutionary change depends on the amount of genetic variation in fitness characters on each host, and the genetic covariance of the same fitness characters across host species can substantially influence the overall course of evolution through the joint effects of natural selection operating on the fitness characters in different host environments, rather than simply resulting from selection on the character in a single host plant environment (Via \& Lande, 1985).

Since selection changes gene frequencies, genetic variation may change at each generation of selection. 
Natural selection is thought to reduce genetic variation through the fixation and elimination of alleles in the population. That continual selection leads to an evolutionary plateau has been confirmed in experiments with small artificial populations (Yoo, 1980; Hill, 1982). Here the reduced level of genetic variation due to selection limits the evolutionary response to further selection. However, the effects of selection on genetic variation for natural populations, where the effective population size is often quite large, have yet to be established (Stearns, 1992). In a large population, it takes a long time for selection to eliminate genetic variation, and mutation will regenerate a certain amount of variation for polygenic characters. Mousseau \& Roff (1987) and Roff \& Mousseau (1987) compared the heritabilities of life history characters and of morphological characters, and a general trend of low genetic variance has been observed for life history characters.

For herbivorous insects, different host use among populations has been studied intensively (Rausher, 1982; Tabashnik, 1983; Hare \& Kennedy, 1986; Scriber, 1986; Via, 1991, 1999). Among these studies, those on Tephritid flies, for example, clearly revealed that there is strong disruptive selection for host plant use, and local populations have achieved different adaptive sets of life history characters through the close association with their host plants (Abrahamson \& Weis, 1997; Feder et al., 1998). Also, within-population genetic variation has been estimated for a wide range of species, and the results from these studies show that there is evolutionary potential for the use of different selective environments (Futuyma \& Moreno, 1988; Jaenike, 1990; Via, 1990). However, relatively few attempts have been made to compare the within-population variation in local populations that have adapted to use different hosts. To understand the dynamics of the evolutionary interaction between host plant and insects, it is important to know whether and how selection influences subsequent evolutionary responses. The present study reports the genetic variation within a population of the herbivorous ladybird beetle, Epilachna vigintioctomaculata and discusses the role played by natural selection for different host plant use on the level of genetic variation maintained within the population.

Epilachna vigintioctomaculata is one of a group of closely related herbivorous ladybird beetles (the E. vigintioctomaculata complex) that have diversified greatly in external morphology and host plant use in and around the Japanese Archipelago. Epilachna vigintioctomaculata inhabits Hokkaido (the main northern island) and the northern part of Honshu (the main central island) in Japan (Katakura, 1981). Epilachna vigintioctomaculata feeds mainly on Solanum tuberosum L. (Solanaceae), the potato in crop fields. Although some additional plants in the family Solanaceae are subsidiarily used by adult beetles, larvae develop almost entirely on S. tuberosum (Katakura, 1981). Some populations in Hokkaido are found on Schizopepon bryoniaefolius Maxim. (Cucurbitaceae) that typically grows in and around forests, but this host is not used as a host plant in Honshu. There has been an observation of adult beetles on this plant in the northernmost part of Honshu (Yasutomi \& Fukuda, personal communication), but no population that is dependent on $S$. bryoniaefolius has been found. Such variation suggests geographical variation in host plant use (Katakura, 1981), as the populations on Hokkaido have depended and persisted on S. bryoniaefolius since their discovery in 1951 (Katakura, 1981). Due to the difference of the host plant habitat, migration between S. bryoniaefolius and $S$. tuberosum seems unlikely, and no population has been recorded that is dependent on both of these host plants (Katakura, 1975). In a previous experiment, populations from Honshu and Hokkaido were reared on both their own and the other population's host plant. When reared on the same plant, beetles for whom it was the normal host performed better than beetles for whom it was a novel host (Ueno et al., 2001). This suggested that the populations have achieved local adaptation in the use of their normal host.

Significant genetic variation in the Honshu population has been detected for growth performance both on $S$. tuberosum and on S. bryoniaefolius (Ueno et al., 1999). When amounts of genetic variation in growth performance on the host plants were compared, variation on S. tuberosum, the normal host of the Honshu population, was smaller than that on S. bryoniaefolius. The heritability estimates for larval period and pupal weight on $S$. tuberosum were 0.081 and 0.110 , respectively, while the estimates for the analogous performance were 0.305 and 0.555 on S. bryoniaefolius. The particular interest in the present study is to estimate the level of genetic variation within the Hokkaido population and to detect whether a similar pattern of genetic variation exists, but in the opposite direction; and to test whether selection that has been imposed on the Hokkaido population to use $S$. bryoniaefolius, has reduced genetic variation in growth performance on S. bryoniaefolius when compared to genetic variation in growth performance on $S$. tuberosum.

\section{Materials and methods}

Epilachna vigintioctomaculata is a univoltine species. In June 1996, overwintered beetles were collected on S. bryoniaefolius at a suburb of Sapporo City, Hokkaido. The beetles were kept under $22^{\circ} \mathrm{C}, 16 \mathrm{~L}-8 \mathrm{D}$ conditions, and these conditions were maintained throughout this

(c) The Genetics Society of Great Britain, Heredity, 87, 1-7. 
experiment. The beetles were provided with fresh leaves of $S$. bryoniaefolius every other day. The ovipositions of egg clutches by the overwintered generation were checked and egg clutches were collected daily.

Full-sib families were made by confining a male and female pair in a plastic case. Since virtually all females would have copulated and stored sperm before collection, the experiment was started after at least three copulations for each female were confirmed. This was done to ensure a high level of last male paternity. Thus, although the experiment was arranged as a split brood design, a full-sib family would have been virtually certain. In the following statistical calculations, larvae from each female were regarded as full-sib progenies, assuming complete last male paternity.

For each female, 40 eggs were collected from several egg clutches. Of these 40 eggs, 20 were reared on $S$. tuberosum and 20 on $S$. bryoniaefolius. These larvae were reared individually in a plastic case with a sheet of filter paper to keep adequate moisture. Fresh host plant leaves were supplied every other day. Larval development was checked daily. On the day of pupation, fresh weight was measured to $0.1 \mathrm{mg}$ with a microbalance.

Survivorship was analysed using log-likelihood-ratio analysis to detect the effects of family, host and family $x$ host interaction. Larval period and pupal weight were transformed to a logarithmic scale before analyses, and mixed-model ANOVAs were performed to detect the contribution of the factors in the total variation in growth performance, setting family and family $\times$ host interaction as random, and sex and host as fixed effects. With this statistical procedure, the variance component due to the family main effect detects the covariance in the performance across the host plants. When divided by the interaction, the family main effects with $F$-values above $97.5 \%$ indicate significant positive genetic covariation, while those with $F$-values below $2.5 \%$ indicate significant negative genetic covariation, at the $5 \%$ level (Fry, 1992). Two further ANovas were also performed to evaluate the among-family variance of performance on each host plant separately. All ANOvAs were performed using PROC GLM in SAS.

The PROC VARCOMP in SAS was used to estimate the proportion of phenotypic variation in growth performance attributable to the among- and within-family variances. Broad sense heritabilities were calculated using the variance components as $h^{2}=2 \sigma^{2}$ (Family)/ $\left[\sigma^{2}\right.$ (Family) $+\sigma^{2}$ (Error) $]$. To compare variance components and heritabilities between host plants, the jackknife procedure was used (Lynch \& Walsh, 1998). Here, estimates were jackknifed with one family omitted each time so that the total number of iterations was equal to the number of families (Sokal \& Rohlf, 1981). To detect whether variance components and heritabilities differ between host plants, pseudovalues were analysed with a two-way ANOVA with family and host as factors.

Genetic correlation of the same performance character across the hosts was estimated using the family means as $r_{\mathrm{m}}=\operatorname{Cov}(\mathrm{X}, \mathrm{Y}) /[\operatorname{Var}(\mathrm{X}) \operatorname{Var}(\mathrm{Y})]^{1 / 2}$, where $\operatorname{Cov}(\mathrm{X}, \mathrm{Y})$ is the covariance of the family mean of the character reared on one host plant and family mean of the same character reared on the other host, and $\operatorname{Var}(\mathrm{X})$ is the variance of the family mean on one host plant (Via, 1984; Via \& Conner, 1995). Genetic correlation was also estimated using variance components obtained from PROC VARCOMP adapted to the mixed model. Here genetic correlation was estimated as $r_{\mathrm{G}}=\sigma^{2}$ (Family)/ $\left[\sigma^{2}\right.$ (Family $\times$ Host $)+\sigma^{2}$ (Family) $]($ Fry, 1992). The jackknife procedure was used to calculate the correlations with their standard errors. In the above calculation of variance components, the TYPE1 option in PROC VARCOMP was used because in this option estimate is not restricted to being positive.

\section{Results}

In total, 421 beetles were obtained from 13 families. Log-likelihood-ratio analysis on survivorship did not detect any significant effect for host, family nor family $\times$ host interaction (host: d.f. $=1, G=0.53, P=0.467$; family: d.f. $=12, G=12.1, P=0.436$; family $\times$ host: d.f. $=12, G=10.0, \quad P=0.614)$. Larval period and pupal weight were significantly influenced by host plants (Table 1). Those reared on $S$. tuberosum, the novel host for the population, showed a shorter larval period than those reared on $S$. bryoniaefolius, the normal host. Larvae which were reared on $S$. tuberosum achieved heavier pupal weight than their siblings which were

Table 1 Percentage survival and means (standard errors) for larval period and pupal weight in a herbivorous ladybird beetle, Epilachna vigintioctomaculata reared on Schizopepon bryoniaefolius or Solanum tuberosum. Sample sizes are given in parentheses

\begin{tabular}{lll}
\hline & \multicolumn{2}{c}{ Host } \\
\cline { 2 - 3 } & $\begin{array}{c}\text { Schizopepon } \\
\text { bryoniaefolius }\end{array}$ & $\begin{array}{c}\text { Solanum } \\
\text { tuberosum }\end{array}$ \\
\hline $\begin{array}{l}\text { Larval period (days) } \\
\text { Male }\end{array}$ & $23.2 \pm 0.1(131)$ & $21.3 \pm 0.1(101)$ \\
$\quad$ Female & $23.3 \pm 0.2(87)$ & $21.3 \pm 0.1(102)$ \\
Pupal weight (mg) & & \\
$\quad$ Male & $45.9 \pm 0.5(131)$ & $51.0 \pm 0.6(101)$ \\
$\quad$ Female & $50.0 \pm 0.6(87)$ & $53.9 \pm 0.7(102)$ \\
$\quad \begin{array}{l}\text { Survival } \\
\text { to adult (\%) }\end{array}$ & 83.8 & 78.1 \\
\hline
\end{tabular}


raised on $S$. bryoniaefolius. This overall tendency in between-plant difference was observed in both males and females. Females were significantly heavier than male siblings, whereas larval periods were not significantly different between the sexes (Tables 1,2).

The mixed-model ANOVAs detected significant family $\times$ host interaction for both the larval period and pupal weight. The family main effect in the mixed-model ANOVAs, which indicates genetic covariance across hosts, was not significant for the larval period and pupal weight with the two-tailed test (Table 2 ). A strong family $\times$ host interaction was detected by the rank correlation plot of family mean (Fig. 1). Here, the plot shows least squares mean of families adjusted for the effect of sex. Substantial changes in relative rank position were observed in some cases, and no significant rank correlations were detected (larval period: $r_{\mathrm{s}}=-0.269, P>0.05$; pupal weight: $\left.r_{\mathrm{s}}=0.115, P>0.05\right)$.

From the ANOVA performed for growth performance on S. tuberosum and S. bryoniaefolius separately, significant among-family variance was detected in each case (Table 3). ANOVA detected significant among-family variance for both the larval period and pupal weight. There were large, although not significant, differences between the estimates of the among-family variance components between the hosts (larval period: d.f. $=1$, $12, F=0.610, P=0.450$; pupal weight: d.f. $=1,12$, $F=1.038, P=0.328$ ). For the within-family variance components, however, estimated differences were very small for both traits (larval period: d.f. $=1,12, F=0.226$, $P=0.643$; pupal weight: d.f. $=1,12, \quad F=0.001$, $P=0.982$ ) (Table 4). Broad sense heritabilities were moderate for growth performances on $S$. tuberosum, and rather lower heritabilities were obtained for both the larval period and pupal weight on S. bryoniaefolius (Table 4). These estimates also were not significantly different (larval period: d.f. $=1, \quad 12, \quad F=0.887$, $P=0.365$; pupal weight: d.f. $=1,12, \quad F=1.539$, $P=0.238$ ).

The genetic correlation calculated with variance components reflected the above results of the mixedmodel ANovas (Table 5). The genetic correlations for both components of growth performances were not different from zero. Estimated values of family mean genetic correlations $\left(r_{\mathrm{m}}\right)$ were in agreement with those based on variance components $\left(r_{\mathrm{G}}\right)$.

\section{Discussion}

The particular interest of the present study was to estimate genetic variation within the Hokkaido population and to detect the effects of past selection of host plant use on the pattern of within-population genetic variations. Although the estimates of variance components had large standard errors and statistical significance was not obtained, the present results found rather

Table 2 ANOvas to compare variations in larval period and pupal weight of Epilachna vigintioctomaculata reared on Schizopepon bryoniaefolius or Solanum tuberosum. $r^{2}$ shows the fit of the overall model

\begin{tabular}{|c|c|c|c|c|c|c|c|c|}
\hline \multirow[b]{2}{*}{ Source } & \multicolumn{4}{|c|}{ Larval period } & \multicolumn{4}{|c|}{ Pupal weight } \\
\hline & d.f. & MS & $F$ & $P$ & d.f. & MS & $F$ & $P$ \\
\hline Sex & 1 & 0.001 & 0.003 & 0.9601 & 1 & 46.801 & 31.136 & $<0.0001$ \\
\hline Host & 1 & 60.039 & 43.586 & $<0.0001$ & 1 & 56.629 & 6.470 & 0.0254 \\
\hline Family & 12 & 1.763 & 1.226 & 0.3647 & 12 & 4.120 & 0.448 & 0.9107 \\
\hline Family $\times$ Host & 12 & 1.440 & 3.564 & $<0.0001$ & 12 & 9.215 & 6.131 & $<0.0001$ \\
\hline Error & 394 & 0.404 & & & 394 & 1.503 & & \\
\hline$r^{2}$ & & & & & 0.3 & & & \\
\hline
\end{tabular}

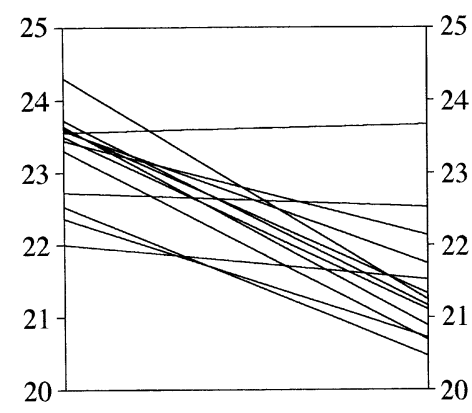

Larval period on Larval period on S. bryoniaefolius (day) S. tuberosum (day)

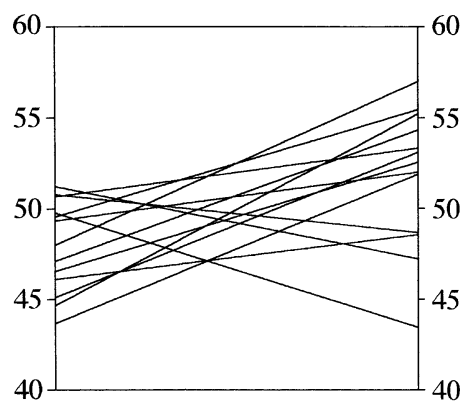

Pupal weight on Pupal weight on S. bryoniaefolius $(\mathrm{mg}) \quad$ S. tuberosum $(\mathrm{mg})$
Fig. 1 Variation among full-sib families of Epilachna vigintioctomaculata for larval period (left) and pupal weight (right). Least squares mean adjusted for effect of sex for each family reared on Schizopepon bryoniaefolius is shown on left axis with corresponding mean of siblings reared on Solanum tuberosum on right axis. Lines connect the means for each family. Nonparallelism is the expression of family $\times$ host plant interaction. 
Table 3 ANOvAs to compare variations in larval period and pupal weight of Epilachna vigintioctomaculata reared on Schizopepon bryoniaefolius or Solanum tuberosum. $r^{2}$ shows the fit of the overall model

\begin{tabular}{|c|c|c|c|c|c|c|c|c|}
\hline Source & \multicolumn{4}{|c|}{ Larval period } & \multicolumn{4}{|c|}{ Pupal weight } \\
\hline Sex & 1 & 0.010 & 0.021 & 0.8843 & 1 & 41.072 & 27.298 & $<0.0001$ \\
\hline Family & 12 & 1.317 & 2.839 & 0.0013 & 12 & 4.940 & 3.283 & 0.0002 \\
\hline Error & 204 & 0.464 & & & 204 & 1.505 & & \\
\hline \multicolumn{9}{|c|}{ Solanum tuberosum } \\
\hline Sex & 1 & 0.021 & 0.061 & 0.8051 & 1 & 10.666 & 7.190 & 0.0080 \\
\hline Family & 12 & 1.681 & 4.931 & $<0.0001$ & 12 & 8.002 & 5.395 & $<0.0001$ \\
\hline Error & 189 & 0.341 & & & 189 & 1.483 & & \\
\hline$r^{2}$ & 0.238 & & & & 0.282 & & & \\
\hline
\end{tabular}

Table 4 Jackknife estimates for variance components $(\times 100)$ for analyses in Table 3 and for broad sense heritabilities calculated using the variance component. Variance components were estimated using TYPE1 with host and sex as fixed effects. The parameters were jackknifed with each family omitted once so that the total number of iterations was equal to the number of families. Standard errors are given in parentheses

\begin{tabular}{lcccc}
\hline & \multicolumn{2}{c}{ Larval period } & \multicolumn{2}{c}{ Pupal weight } \\
\cline { 2 - 4 } & S. $b$. & $S . t$. & S. $b$. & S. $t$. \\
\hline Among-family & $0.052(0.032)$ & $0.121(0.078)$ & $0.207(0.080)$ & $0.409(0.176)$ \\
Within-family & $0.464(0.068)$ & $0.425(0.031)$ & $1.502(0.234)$ & $1.492(0.493)$ \\
Heritability & $0.198(0.127)$ & $0.482(0.273)$ & $0.241(0.092)$ & $0.429(0.120)$ \\
\hline
\end{tabular}

S. b., Schizopepon bryoniaefolius; S. t., Solanum tuberosum.

Table 5 Genetic correlation estimates of Epilachna vigintioctomaculata between the same characters across different plant species with their $95 \%$ confident limits in parentheses. Genetic correlations were estimated using variance and covariance of the family means $\left(r_{\mathrm{m}}\right)$ and using variance components of the mixed model $\left(r_{\mathrm{G}}\right)$

\begin{tabular}{ccc}
\hline & Larval period & Pupal weight \\
\hline$r_{\mathrm{m}}$ & $0.130(0.355,0.560)$ & $0.152(0.590,0.354)$ \\
$r_{\mathrm{G}}$ & $0.019(0.647,0.668)$ & $0.578(0.928,0.317)$ \\
\hline
\end{tabular}

small among-family variance components in beetles raised on $S$. bryoniaefolius compared to those raised on $S$. tuberosum. The within-family variance components suggested no apparent difference between host plants. The pattern of variance components resulted in higher estimated heritabilities for growth performances on $S$. tuberosum than those on S. bryoniaefolius. Furthermore, the performance characters were not genetically correlated across hosts, suggesting a different genetic basis for growth performance on each host, and thereby allowing genetic variations for growth performance on each host to change independently in the course of adaptation to use the host plants.

The genetic basis for host plant use indicated by the present results was consistent with the results from the Honshu population, which showed adaptation to use of the normal host, S. tuberosum. For the Honshu population, smaller among-family variance components were found on $S$. tuberosum than those on S. bryoniaefolius (Ueno et al., 1999). Thus, both the Hokkaido and Honshu populations indicated smaller genetic variation in growth performance on their normal host species. These results may suggest the possibility that the natural selection on the two populations to use their host plant has reduced the level of genetic variation within each population.

The above results indicate that the ability to exploit the novel host is not likely to be genetically constrained either in terms of genetic variation or genetic correlation. A lack of genetic constraint has been suggested for other herbivorous species. When experiments were made on normal and novel host plants, previous experiments detected positive or no genetic correlation (Rausher, 1984; Via, 1984; Hare \& Kennedy, 1986; James

(C) The Genetics Society of Great Britain, Heredity, 87, 1-7. 
et al., 1988; Karowe, 1990; Fox, 1993), and significant genetic variation in growth performance on each plant (Rausher, 1984; Hare \& Kennedy, 1986). These results and the results on E. vigintioctomaculata that suggest the general lack of genetic constraints, indicate that behavioural and ecological factors may be the primary influence on host plant use and host range determination.

A previous study that compared the growth performance of the Honshu and Hokkaido populations suggested differential local adaptation to use $S$. tuberosum in the Honshu and S. bryoniaefolius in the Hokkaido population (Ueno et al., 2001). The present results on the genetic structure of the Hokkaido population and of the Honshu population (Ueno et al., 1999) suggest that a genetic trade-off or absence of genetic variation is not responsible for the specialization of $E$. vigintioctomaculata in the use of different host plants. A mathematical model developed by Fry (1996) showed that a significant genotype $\times$ host interaction could be sufficient to allow the evolution of host specialization. The reduced among-family variation on host plants to which the beetles are locally adapted, possibly through selection, seems to be consistent with the evolutionary process of specialization suggested by the model of Fry (1996), where the difference in performance is generated by a higher rate of the fixation of adaptive mutations on the specialized host and the accumulation of deleterious mutations on the other host.

It is also worthwhile to note that the direction of specialization in the model is dependent on which host is initially used by the greater fraction of the population (Fry, 1996). Schizopepon bryoniaefolius is more abundant as a host resource for ladybird beetles in Hokkaido than in Honshu, possibly due to the cooler climatic conditions in Hokkaido. In Honshu, the distribution of $S$. bryoniaefolius is restricted to high altitude mountain regions (Satake et al., 1982), and an E. vigintioctomaculata population dependent on $S$. bryoniaefolius has never been found. It is not possible to detect the ancestral distribution of the host plants definitively. However, if the pattern of host plant distribution was similar to the present distribution, it might be possible that the difference in availability between host plants has led to the different direction of specialization found in the present species.

It is well known that the magnitude of genetic and environmental variance components changes with environmental conditions. In studies on size characters in birds, reduced heritable variation has been reported in nutritionally poor conditions (Van Noordwijk et al., 1988; Larsson, 1993; Merilä, 1997), and some specific host properties on genetic variation were reported in the cowpea weevil (Kawecki, 1995). Although whether factors which are unrelated to past selective forces affect the genetic properties in E. vigintioctomaculata is not known, the consistent results from the two populations suggest that the effect of selection is predominant.

For life history characters, low genetic variance has generally been observed (Mousseau \& Roff, 1987; Roff \& Mousseau, 1987). The low heritabilities of growth performance on the normal host plant estimated in the present study are compatible with the trend. It is important to note, however, that the significant among-family variation detected on each host plant contains nonadditive sources of genetic variation. Thus, although the values provide an upper limit of genetic variation, the amount of additive genetic variation remains to be estimated.

\section{Acknowledgements}

We express our sincere thanks to M. Bradley and P. de Jong for comments on the manuscript. Comments from two referees very much improved the manuscript. This study was supported in part by a Grant-in-Aid for Scientific Research (No. 09440258) from the Ministry of Education, Science and Culture, Japan.

\section{References}

ABRAHAMSON, w. G. AND WEIS, A. E. 1997. Evolutionary Ecology Across Three Trophic Levels. Princeton University Press, Princeton, NJ.

FEDER, J. L., BERLOCHER, S. H. AND OPP, S. B. 1998. Sympatric host-race formation and speciation in Rhagoletis (Diptera: Tephritidae): a tale of two species for Charles D. In: Mopper, S. and Strauss, S. Y. (eds) Genetic Structure and Local Adaptation in Natural Insect Populations, pp. 408-441. Chapman \& Hall, New York.

Fox, C. W. 1993. A quantitative genetic analysis of oviposition preference and larval performance on two hosts in the bruchid beetle, Callosobruchus maculatus. Evolution, 47, 166-175.

FRY, J. D. 1992. The mixed model analysis of variance applied to quantitative genetics: biological meaning of the parameters. Evolution, 46, 540-550.

FRY, J. D. 1996. The evolution of host specialization: are tradeoffs overrated? Am. Nat., 148, S84-S107.

FUTUYMA, D. J. AND MORENO, G. 1988. The evolution of ecological specialization. Ann. Rev. Ecol. Syst., 19, 207-233.

HARE, J. D. AND KENNEDy, G. G. 1986. Genetic variation in plant-insect associations: survival of Leptinotarsa decemlineata populations on Solanum carolinense. Evolution, $\mathbf{4 0 ,}$ 1031-1043.

HILL, W. G. 1982. Predictions of response to artificial selection from new mutations. Genet. Res., 40, 255-278.

JAENIKE, J. 1990. Host specialization in phytophagous insects. Ann. Rev. Ecol. Syst., 21, 243-273.

JAMES, A. C., JAKUBCZAK, J., RIDLEY, M. P. AND JAENIKE, J. 1988. On the causes of monophagy in Drosophila quinaria. Evolution, 42, 626-630.

(c) The Genetics Society of Great Britain, Heredity, 87, 1-7. 
KAROWE, D. N. 1990. Predicting host range evolution: colonization of Coronilla varia by Colias philodice (Lepidoptera: Pieridae). Evolution, 44, 1637-1647.

KATAKURA, H. 1975. Schizopepon bryoniaefolius as a native host plant for Henosepilachna vigintioctomaculata (Coleoptera: Coccinellidae) in Hokkaido. Appl. Entomol. Zool., 10, 103-107.

KATAKURA, H. 1981. Classification and evolution of the phytophagous ladybirds belonging to Henosepilachna vigintioctomaculata complex (Coleoptera, Coccinellidae). J. Fac. Sci. Hokkaido University, VI (Zool.), 22, 301-378.

KAWECKI, T. J. 1995. Expression of genetic and environmental variation for life history characters on the usual and novel hosts in Callosobruchus maculatus (Coleoptera: Bruchidae). Heredity, 75, 70-76.

LARSSON, K. 1993. Inheritance of body size in the barnacle goose under different environmental conditions. J. Evol. Biol., 6, 195-208.

LYNCH, M. AND WALSH, B. 1998. Genetics and Analysis of Quantitative Traits. Sinauer Associates, Sunderland, MA.

MERILÄ, J. 1997. Expression of genetic variation in body size of the collared flycatcher under different environmental conditions. Evolution, 51, 526-536.

MOUSSEAU, T. A. AND ROFF, D. A. 1987. Natural selection and the heritability of fitness components. Heredity, 59, 181-197.

RAUSHER, M. D. 1982. Population differentiation in Euphydryas editha butterflies: larval adaptation to different hosts. Evolution, 36, 581-590.

RAUSHER, M. D. 1984. Trade-offs in performance on different hosts: Evidence from within and between site variation in the beetle, Deloyala guttata. Evolution, 38, 582-595.

ROFF, D. A. AND MOUSSEAU, T. A. 1987. Quantitative genetics and fitness: lessons from Drosophila. Heredity, 58, 103-118.

SATAKE, S., OHWI, J., KitAMURA, S., WATARI, S. ET $A L$. 1982. Wild Flowers of Japan. Heibonsha Ltd., Publishers, Tokyo (in Japanese).

SCRIBER, J. M. 1986. Origins of the regional feeding abilities in the tiger swallowtail butterfly: ecological monophagy and the Papilio glaucus australis subspecies in Florida. Oecologia, 71, 94-103.

SOKAL, R. B. AND ROHLF, F. J. 1981. Biometry, 2nd edn. Freeman, San Francisco.
STEARNS, S. C. 1992. The Evolution of Life Histories. Oxford University Press, New York.

TABASHNIK, B. E. 1983. Host range evolution: the shift from native legume hosts to alfalfa by the butterfly, Colias philodice eriphyle. Evolution, 37, 150-162.

UENO, H., FUJIYAMA, N., IRIE, K., SATO, Y. ET AL. 1999. Genetic basis for established and novel host plant use in a herbivorous ladybird beetle, Epilachna vigintioctomaculata. Entomol. Exp. Appl., 91, 245-250.

UENO, H., HASEgAWA, Y., FUJIYAMA, N. AND KATAKURA, H. 2001. Population differentiation in host plant use in a herbivorous ladybird beetle, Epilachna vigintioctomaculata. Entomol. Exp. Appl., 99, 263-265.

VAN NOORDWIJK, A. J., VAN BALEN, J. H. AND SCHARLOO, w. 1988. Heritability of body size in a natural population of the great tit (Parus major) and its relation to age and environmental conditions during growth. Genet. Res., 51, 149-162.

VIA, S. 1984. The quantitative genetics of polyphagy in an insect herbivore. II. Genetic correlations in larval performance within and among host plants. Evolution, 38, 896-905.

VIA, S. 1990. Ecological genetics and host adaptation in herbivorous insects: the experimental study of evolution in natural and agricultural systems. Ann. Rev. Entomol., 35, 421-446.

VIA, s. 1991. The genetic structure of host plant adaptation in a spatial patchwork: demographic variability among reciprocally transplanted pea ahphid clones. Evolution, 45, 827-852.

VIA, S. 1999. Reproductive isolation between sympatric races of pea aphids. I. Gene flow restriction and habitat choice. Evolution, 53, 1446-1457.

VIA, S. AND CONNER, J. 1995. Evolution in heterogeneous environments: genetic viability within and across different grains in Tribolium castaneum. Heredity, 74, 80-90.

VIA, S. AND LANDE, R. 1985. Genotype-environment interaction and the evolution of phenotypic plasticity. Evolution, 39, $505-522$.

Yoo, в. H. 1980. Long-term selection for a quantitative character in large replicate populations of Drosophila melanogaster. I. Response to selection. Genet. Res., 35, $1-17$. 